\title{
Long-Term Cost Effectiveness of Oral Semaglutide Versus Empagliflozin and Sitagliptin for the Treatment of Type 2 Diabetes in the Swedish Setting
}

\author{
Björn Eliasson $^{1}$ (D) Åsa Ericsson ${ }^{2} \cdot$ Adam Fridhammar $^{3} \cdot$ Andreas Nilsson $^{3} \cdot$ Sofie Persson $^{3,4} \cdot$ Barrie Chubb $^{5}$
}

Accepted: 5 December 2021 / Published online: 21 January 2022

(c) The Author(s) 2022

\begin{abstract}
Objective The aim of this study was to assess the cost effectiveness of oral semaglutide versus other oral glucose-lowering drugs for the management of type 2 diabetes (T2D) in Sweden.

Methods The Swedish Institute for Health Economics Diabetes Cohort Model was used to assess the cost effectiveness of oral semaglutide $14 \mathrm{mg}$ versus empagliflozin $25 \mathrm{mg}$ and oral semaglutide $14 \mathrm{mg}$ versus sitagliptin $100 \mathrm{mg}$, using data from the head-to-head PIONEER 2 and 3 trials, respectively, in which these treatments were added to metformin ( \pm sulphonylurea). Base-case and scenario analyses were conducted. Robustness was evaluated with deterministic and probabilistic sensitivity analyses.

Results In the base-case analyses, greater initial lowering of glycated haemoglobin levels with oral semaglutide versus empagliflozin and oral semaglutide versus sitagliptin, respectively, resulted in reduced incidences of micro- and macrovascular complications and was associated with lower costs of complications and indirect costs. Treatment costs were higher for oral semaglutide, resulting in higher total lifetime costs than with empagliflozin (Swedish Krona [SEK] 1,245,570 vs. $1,210,172$ ) and sitagliptin (SEK1,405,789 vs. 1,377,381). Oral semaglutide was shown to be cost effective, with an incremental cost-effectiveness ratio (ICER) of SEK239,001 per quality-adjusted life-year (QALY) compared with empagliflozin and SEK120,848 per QALY compared with sitagliptin, from a payer perspective. ICERs were lower at SEK191,721 per QALY compared with empagliflozin and SEK95,234 per QALY compared with sitagliptin from a societal perspective. Results were similar in scenario analyses that incorporated cardiovascular effects, and also in sensitivity analyses.

Conclusions In a Swedish setting, oral semaglutide was cost effective compared with empagliflozin and sitagliptin for patients with T2D inadequately controlled on oral glucose-lowering drugs.

Trial Registration ClinicalTrials.gov: NCT02863328 (PIONEER 2; registered 11 August 2016) and NCT02607865 (PIONEER 3; registered 18 November 2015).
\end{abstract}

Björn Eliasson

bjorn.eliasson@gu.se

1 Department of Molecular and Clinical Medicine, Institute of Medicine, University of Gothenburg, Sahlgrenska

University Hospital, 41345 Gothenburg, Sweden

2 Novo Nordisk Scandinavia AB, Malmö, Sweden

3 The Swedish Institute for Health Economics, Lund, Sweden

4 Department of Clinical Sciences, Lund University, Health Economics Unit, Lund, Sweden

5 Novo Nordisk A/S, Søborg, Denmark 


\section{Plain Language Summary}

For any disease, it is important to consider whether new treatments, which may be more effective but also more expensive, are worth paying for compared with treatments that are already being used. This is called a cost-effectiveness analysis and helps health authorities and other organisations (such as insurance companies) that pay for medications to decide whether or not to pay for the new treatment. Cost effectiveness differs between individual countries because each has its own health system, health costs and approved treatments. Semaglutide is a type of medication called a glucagon-like peptide-1 receptor agonist (or GLP-1RA) that is used by people with type 2 diabetes to help control their blood glucose (sugar). Semaglutide is administered by injection but has recently become the first GLP-1RA to be available in a once-daily oral (tablet) form. We used information from the Swedish Institute for Health Economics and two clinical trials of oral semaglutide that compared it with other oral glucose-lowering drugs-empagliflozin and sitagliptin - to work out whether oral semaglutide was a cost-effective treatment in Sweden. We found that oral semaglutide was more expensive than empagliflozin and sitagliptin over the entire time on treatment but also led to greater lowering of blood sugar. This means that patients had fewer other illnesses linked to diabetes and lower health costs as a result. Balancing the higher upfront cost of the drug versus savings from fewer illnesses linked to diabetes, we found that in Sweden, oral semaglutide was cost effective compared with empagliflozin and sitagliptin.

\section{Introduction}

Type 2 diabetes (T2D) and its complications account for a substantial health and economic burden [1]. Costs are expected to substantially rise over time; the absolute global economic burden is expected to increase from US dollars (US\$) 1.3 trillion in 2015 to more than US\$2.1 trillion by 2030 [2]. The costs of diabetes include both direct costs from medical care as well as indirect costs incurred through loss of productivity or earnings, both of which are important contributors to the overall global economic burden [1, 2]. In Sweden alone, the total costs of hospital-based care ( $€ 269$ million) and absence from work related to diabetes complications ( $€ 884$ million) were $€ 1153$ million ( $€ 2943$ per person with diabetes) in 2016 [1].

Glycaemic control is a key therapeutic goal in T2D because elevated levels of glycated haemoglobin $\left(\mathrm{HbA}_{1 \mathrm{c}}\right)$ are associated with an increased risk of complications and mortality [3]. For example, in Swedish studies, the excess risk of cardiovascular events was higher for patients with T2D compared with controls [4]; however, the risk was similar to that of the general population in patients with ontarget $\mathrm{HbA}_{1 \mathrm{c}}$ levels $[5,6]$. Even modest improvements in $\mathrm{HbA}_{1 \mathrm{c}}$ were shown to reduce complications and achieve cost savings [7]. Nevertheless, in Sweden, as in other countries, many patients with T2D fail to achieve or maintain adequate $\mathrm{HbA}_{1 \mathrm{c}}$ levels $[8,9]$.

Due to their ability to lower $\mathrm{HbA}_{1 \mathrm{c}}$ without increasing hypoglycaemia risk, international guidelines recommend glucagon-like peptide-1 receptor agonists (GLP-1RAs), sodium-glucose cotransporter-2 inhibitors (SGLT2is) and dipeptidyl peptidase-4 inhibitors (DPP4is) as options for add-on therapy for patients with $\mathrm{HbA}_{1 \mathrm{c}}$ inadequately controlled on metformin [10]. GLP-1RAs and SGLT2is also have a weight-loss effect [10]. Furthermore, GLP-1RAs and SGLT2is with proven cardiovascular benefit are also recommended for patients with established atherosclerotic cardiovascular disease (CVD), heart failure and/or chronic kidney disease, regardless of $\mathrm{HbA}_{1 \mathrm{c}}$, and should be considered for those at high risk of CVD [11].

Until recently, GLP-1RAs have only been available in injectable formulations, which may have represented a barrier to their greater use [12]. However, oral semaglutide, a novel formulation of the GLP-1RA semaglutide with the absorption enhancer sodium $N$-(8-[2-hydroxybenzoyl] amino) caprylate, has been developed for once-daily oral administration $[12,13]$. The efficacy and safety, including cardiovascular safety, of oral semaglutide have been demonstrated in the PIONEER clinical trial programme [14-21].

In PIONEER 2, once-daily oral semaglutide $14 \mathrm{mg}$ was superior to the once-daily SGLT2i empagliflozin $25 \mathrm{mg}$ in reducing $\mathrm{HbA}_{1 \mathrm{c}}$ at 26 weeks in patients with T2D uncontrolled on metformin when evaluated using the treatment policy estimand, which included outcomes in patients regardless of treatment discontinuation or rescue medication use (estimated treatment difference [ETD] $-0.4 \%$ (95\% confidence interval [CI] -0.6 to -0.3$) ; p<0.0001$ ) [15]. $\mathrm{HbA}_{1 \mathrm{c}}$ was also significantly reduced versus empagliflozin at 52 weeks using the treatment policy estimand, and at 26 and 52 weeks when assessed by the trial product estimand, which assumed that patients remained on treatment without rescue medication use [15]. Body weight was reduced with both treatments, but with no significant difference between them at weeks 26 or 52 using the treatment policy estimand [15]. However, oral semaglutide provided a significantly greater weight reduction at week 52 (but not at week 26) when assessed by the trial product estimand (ETD $-0.9 \mathrm{~kg}$ [95\% CI -1.6 to -0.2 ]; $p=0.0114$ vs. empagliflozin) [15].

In PIONEER 3, once-daily oral semaglutide $14 \mathrm{mg}$ was superior to the once-daily DPP4i sitagliptin 100 $\mathrm{mg}$ in reducing $\mathrm{HbA}_{1 \mathrm{c}}$ at 26 weeks in patients with $\mathrm{T} 2 \mathrm{D}$ uncontrolled on metformin with or without sulphony- 
lurea using the treatment policy estimand (ETD $-0.5 \%$ [95\% CI -0.6 to -0.4 ]; $p<0.001)$ [16]. $\mathrm{HbA}_{1 \mathrm{c}}$ was also significantly reduced versus sitagliptin at 52 and 78 weeks using the treatment policy estimand and at all three timepoints using the trial product estimand [16]. Oral semaglutide $14 \mathrm{mg}$ was also superior to sitagliptin for reduction in body weight at week 26 (ETD $-2.5 \mathrm{~kg}$ [95\% CI -3.0 to -2.0$]$; $p<0.001$ ) using the treatment policy estimand, and a significant difference was maintained at weeks 52 and 78 [16]. Oral semaglutide also provided significantly greater weight loss at all three timepoints when assessed by the trial product estimand $(p<0.001)$ [16].

Using the treatment effects seen in the PIONEER 2 and 3 trials, the present study was designed to assess the long-term cost effectiveness of oral semaglutide $14 \mathrm{mg}$ versus empagliflozin $25 \mathrm{mg}$ and sitagliptin $100 \mathrm{mg}$ in patients uncontrolled on metformin (with or without sulphonylurea) in Sweden.

\section{Methods}

\subsection{Modelling Approach}

Analyses were conducted using the validated Institute for Health Economics Diabetes Cohort Model (IHE-DCM) [22, 23], which has been used to guide reimbursement decisions by the Swedish Dental and Pharmaceutical Benefits Agency (TLV) $[24,25]$ and in other cost-effectiveness analyses in Sweden [26-28] and internationally [29].

The model is constructed using Markov health states that comprise important micro- and macrovascular complications, as well as premature mortality, resulting from T2D (Fig. S1 in Online Resource 1) [22, 23]. The model allows many user-defined parameters for values, including the baseline characteristics of the cohorts, choice of risk equations, treatment sequences, unit costs and quality of life (QoL) weights. In these analyses, the baseline characteristics of the cohorts were taken from the PIONEER 2 and PIONEER 3 trials $[15,16]$ and included patient demographics (age, sex, race/ethnicity, diabetes duration and smoking status), biomarkers of T2D ( $\mathrm{HbA}_{1 \mathrm{c}}$, systolic and diastolic blood pressure, total cholesterol, low- and high-density lipoprotein cholesterol, triglycerides, body mass index, heart rate, white blood cell count and estimated glomerular filtration rate) and pre-existing complications (eye disease, lower extremity disease, kidney disease and cardiovascular conditions) (Table S1 in Online Resource 1).

The micro- and macrovascular health states used in the IHE-DCM represent the most important complications related to T2D. To capture macrovascular complications, the user can choose from four sets of risk equations [30-33]. The current base-case analysis simulations used macrovascular risk equations from the National Diabetes Register
(NDR) [32] and mortality risk equations from the UK Prospective Diabetes Study Outcomes Model (UKPDS-OM2) [31]. Data on microvascular complications were based on models by Eastman et al. [34] and Bagust et al. [35].

The cycle length was 1 year, with a maximum time horizon of 40 years to ensure that long-term effects were captured. A discount rate of $3 \%$ was assumed for both costs and health gains, in line with methodological guidelines for Swedish cost-effectiveness analyses [36].

Model outputs included direct costs (treatment, microand macrovascular costs), indirect costs and quality-adjusted life-years (QALYs). Incremental cost-effectiveness ratios (ICERs) were calculated from the payer's perspective (without indirect costs) and from a societal perspective (including indirect costs).

More information about the model is provided in Online Resource 1.

\subsection{Base-Case and Scenario Analyses}

At the start of the simulation, patients who were uncontrolled on metformin (or metformin \pm sulphonylurea in PIONEER 3) began treatment. Treatment was either oral semaglutide (escalated to $14 \mathrm{mg}$ once daily) or empagliflozin (25 mg once daily) as described in PIONEER 2 [15], or dose-escalated oral semaglutide or sitagliptin $(100 \mathrm{mg}$ once daily) as described in PIONEER 3 [16]. Treatment effects at 52 weeks, sourced from the PIONEER 2 and PIONEER 3 studies (Table S2 in Online Resource 1) [15, 16], were applied in the first 1-year model cycle. Based on low rates in the trials $[15,16]$, it was assumed that none of the study treatments were associated with hypoglycaemic events. $\mathrm{HbA}_{1 \mathrm{c}}$ levels were assumed to increase at an annual rate of $0.14 \%$, based on the drift seen in the ADOPT study [37]. In the simulation, patients remained on study treatment until $\mathrm{HbA}_{1 \mathrm{c}}$ reached a level of $8.0 \%$, at which point they started basal insulin and discontinued existing study treatments. When $\mathrm{HbA}_{1 \mathrm{c}}$ was no longer controlled with basal insulin, further intensification with the addition of bolus insulin was modelled. For basal-bolus insulin treatment, it was assumed that $\mathrm{HbA}_{1 \mathrm{c}}$ stayed at $8.0 \%$ for the remaining cycles of the simulation. For rescue basal insulin and basal-bolus insulin, treatment effects (including initial $\mathrm{HbA}_{1 \mathrm{c}}$ reductions of $1.44 \%$ and $0.71 \%$, respectively) and rates of hypoglycaemic events were taken from the study by Willis et al. [38].

The PIONEER trial programme used two estimands to address two different efficacy questions [39]. The treatment policy estimand reflected the intention-to-treat principle by including all study participants randomly assigned to each treatment, using data regardless of discontinuation of study medications and/or use of additional antidiabetic medications during the trial. The trial product estimand assessed treatment effects under the assumption that patients received 
the study drug for the duration of the trial and did not receive any additional antidiabetic medications [39]. Thus, this estimand was aimed at reflecting the effects of the study medications without the confounding effects of rescue or any other changes in glucose-lowering medication [39]. Although the treatment policy estimand was the primary estimand in PIONEER 2 and PIONEER $3[15,16]$, it includes the effects of rescue medication, which is captured in the current model with basal and bolus insulin use (although other rescue medications could also have been used). The trial product estimand has therefore been used in the current analysis to avoid double counting.

\subsection{Costs and Utilities}

Treatment costs were taken from the TLV database (https:// www.tlv.se/beslut/sok-i-databasen.html). Annual costs were Swedish Krona (SEK) 13,403 for oral semaglutide, SEK6220 for empagliflozin, SEK4582 for sitagliptin, SEK4057 for basal insulin and SEK7703 for basal plus bolus insulin (Table S3 in Online Resource 1). Costs of microand macrovascular complications and hypoglycaemic events (Table S4 in Online Resource 1) were based on a report by Steen Carlsson et al. [40]. For each micro- and macrovascular complication, costs were divided into event cost (one-time costs incurred during the year of event/onset of complication) and state cost (yearly costs incurred during the first and all subsequent years of the disease).

Indirect costs were calculated using the estimated annual salary multiplied by annual productivity loss (i.e., percentage of days absent from work). Data for each component of annual salary were sourced from Statistics Sweden and Ekonomifakta [41, 42] by sex and age group (Table S5 in Online Resource 1). Annual productivity loss due to diabetes-related complications was derived from a recent Swedish registry study [43] (Table S6 in Online Resource 1). Indirect costs per hypoglycaemic event were obtained from the studies by GeelhoedDuijvestijn et al. [44] for non-severe events (SEK15) and Jönsson et al. [45] for severe events (SEK531). All costs, both direct and indirect, were inflation-adjusted to 2019 SEK.

For health-related QoL, the model includes a baseline QoL and uses decrements associated with micro- and macrovascular complications and obesity, as well as age, sex and diabetes duration (not used in this analysis) (Table S7 in Online Resource 1). These QoL disutility weights were primarily sourced from the systematic review by Beaudet et al. [46], which mostly included studies conducted in Europe and North America, and thus were expected to be broadly applicable to the Swedish population. For hypoglycaemia, event-based disutilities, sourced from the study by Evans et al. [47], were applied to each episode (this study was published after the searches for Beaudet et al. were conducted and included data from five countries, including Sweden).

\subsection{Sensitivity Analyses}

The projection of outcomes over patient lifetimes is associated with uncertainty. Subsequently, sensitivity analyses were performed to investigate any factors, assumptions or input data that may substantially influence model results. Twenty sensitivity analyses were conducted to assess the robustness of the base-case result, including probabilistic sensitivity analyses (PSAs; simulating the mean of 1000 possible sets of outcomes based on the standard errors included), changes in cost parameters, the risk equations used, time horizons, reasons for treatment intensification, and associated QoL decrements.

\subsection{Analyses of Additional Cardiovascular Effects}

Oral semaglutide, empagliflozin and sitagliptin have all been the subject of large cardiovascular outcomes trials that assessed their safety (and any potential cardiovascular benefit) in patients with T2D and high cardiovascular risk (established CVD or risk factors) [19, 48, 49]. The direct impact of cardiovascular effects, i.e., not mediated through biomarkers such as $\mathrm{HbA}_{1 \mathrm{c}}$ and systolic blood pressure, was assessed based on data sourced from the PIONEER 6 [19], EMPA-REG OUTCOME [48] and TECOS [49] cardiovascular outcomes trials for oral semaglutide, empagliflozin and sitagliptin, respectively (Table S8 in Online Resource 1). Treatment-specific hazard ratios were derived from the reduction in major cardiovascular adverse events with each treatment versus placebo, when added to standard of care $[19,48,49]$. Although PIONEER 6 included a proportion of patients without established CVD at baseline (but with risk factors), both EMPA-REG OUTCOME and TECOS included only patients with established CVD at baseline. Two scenarios were considered: (1) cardiovascular effects for patients matching the PIONEER 6 inclusion criteria; and (2) cardiovascular effects for all patients in PIONEER 2 and PIONEER 3. The outcomes were calculated using both probabilistic and deterministic sensitivity analyses. The former simulated the mean of 1000 possible sets of outcomes based on the standard errors for cardiovascular outcomes in the studies included.

\section{Results}

\subsection{Base-Case Analyses}

In PIONEER 2, from a mean baseline value of $8.1 \%$, oral semaglutide $14 \mathrm{mg}$ reduced $\mathrm{HbA}_{1 \mathrm{c}}$ by $1.3 \%$ at week 52 , whereas $\mathrm{HbA}_{1 \mathrm{c}}$ was reduced by $0.8 \%$ with empagliflozin $25 \mathrm{mg}$. In PIONEER 3, from a mean baseline value of 8.3\%, oral semaglutide $14 \mathrm{mg}$ reduced $\mathrm{HbA}_{1 \mathrm{c}}$ by $1.3 \%$ at week 


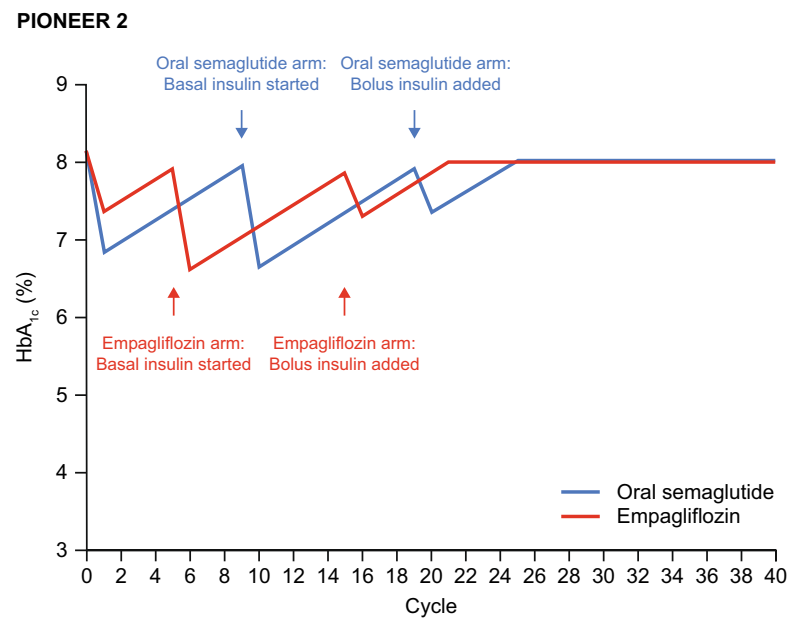

PIONEER 3

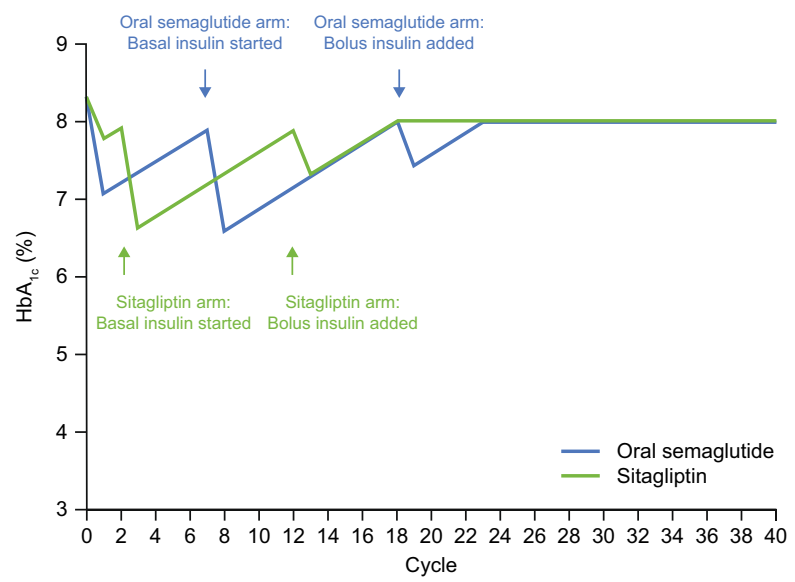

Fig. $1 \mathrm{HbA}_{1 \mathrm{c}}$ trajectories based on PIONEER 2 and PIONEER 3 (base-case analyses). $H b A_{l c}$ glycated haemoglobin
52 , versus a $0.5 \%$ reduction with sitagliptin $100 \mathrm{mg}$. The $\mathrm{HbA}_{1 \mathrm{c}}$ trajectories based on these data for oral semaglutide, empagliflozin and sitagliptin generated in the simulations are presented in Fig. 1. In each case, greater initial $\mathrm{HbA}_{1 \mathrm{c}}$ lowering with oral semaglutide resulted in later initiation of basal insulin.

Treatment costs were higher for oral semaglutide, resulting in higher total lifetime costs than with empagliflozin (SEK1,245,570 vs. 1,210,172) and sitagliptin (SEK1,405,789 vs. 1,377,381) (Table 1). However, greater initial $\mathrm{HbA}_{1 \mathrm{c}}$ reductions from baseline achieved with oral semaglutide compared with empagliflozin or sitagliptin resulted in lower incidences of micro- and macrovascular complications, and therefore lower costs of complications and indirect costs (Table 1). Due to the longer time before insulin initiation modelled for oral semaglutide compared with empagliflozin and sitagliptin (Fig. 1), there were also fewer hypoglycaemic events and lower costs due to hypoglycaemia in the oral semaglutide treatment arms versus comparators.

With fewer complications, projected survival was better with oral semaglutide and this resulted in a health gain of 0.185 QALYs versus empagliflozin and 0.298 versus sitagliptin (Table 1). Oral semaglutide was associated with an ICER of SEK239,001 per QALY compared with empagliflozin and SEK120,848 per QALY compared with sitagliptin, from a payer perspective. ICERs were lower at SEK191,721 per QALY compared with empagliflozin and SEK95,234 per QALY compared with sitagliptin, from a societal perspective (taking into account all health effects and changes in resource use).

Table 1 Cost effectiveness from base-case analyses

\begin{tabular}{|c|c|c|c|c|c|c|}
\hline & \multicolumn{3}{|l|}{ PIONEER 2} & \multicolumn{3}{|l|}{ PIONEER 3} \\
\hline & $\begin{array}{l}\text { Oral semaglutide } \\
14 \mathrm{mg}\end{array}$ & $\begin{array}{l}\text { Empagliflozin } \\
25 \mathrm{mg}\end{array}$ & Increment & $\begin{array}{l}\text { Oral semaglutide } \\
14 \mathrm{mg}\end{array}$ & $\begin{array}{l}\text { Sitagliptin } \\
100 \mathrm{mg}\end{array}$ & Increment \\
\hline Treatment costs & 135,145 & 80,499 & 54,646 & 120,976 & 74,950 & 46,026 \\
\hline Microvascular costs & 208,180 & 214,574 & -6393 & 266,854 & 272,204 & -5350 \\
\hline Macrovascular costs & 255,775 & 259,899 & -4125 & 261,382 & 266,009 & -4627 \\
\hline Hypoglycaemia costs & 1059 & 1700 & -641 & 1169 & 2202 & -1033 \\
\hline Indirect costs & 646,470 & 655,200 & -8730 & 756,576 & 764,217 & -7641 \\
\hline Total cost & $1,245,570$ & $1,210,172$ & 35,399 & $1,405,789$ & $1,377,381$ & 28,408 \\
\hline QALYs & 8.906 & 8.721 & 0.185 & 8.326 & 8.028 & 0.298 \\
\hline ICER, payer perspective & - & - & 239,001 & - & - & 120,848 \\
\hline ICER, societal perspective & - & - & 191,721 & - & - & 95,234 \\
\hline
\end{tabular}

Costs are reported in Swedish Krona

ICER incremental cost-effectiveness ratio, QALYs quality-adjusted life-years 
Table 2 Results from sensitivity analyses

\begin{tabular}{|c|c|c|c|c|c|c|c|c|}
\hline & \multicolumn{4}{|c|}{ Increment for oral semaglutide vs. empagliflozin } & \multicolumn{4}{|c|}{ Increment for oral semaglutide vs. sitagliptin } \\
\hline & $\begin{array}{l}\text { Total cost } \\
\text { (societal) }\end{array}$ & $\begin{array}{l}\text { Change } \\
\text { in } \\
\text { QALYs }\end{array}$ & ICER (payer) & ICER (societal) & $\begin{array}{l}\text { Total cost } \\
\text { (societal) }\end{array}$ & $\begin{array}{l}\text { Change } \\
\text { in } \\
\text { QALYs }\end{array}$ & ICER (payer) & ICER (societal) \\
\hline Base case & 35,399 & 0.185 & 239,001 & 191,721 & 28,408 & 0.298 & 120,848 & 95,234 \\
\hline $\begin{array}{l}\text { Cost of severe hypoglycaemia } \\
+20 \%\end{array}$ & 35,379 & 0.185 & 238,897 & 191,616 & 28,376 & 0.298 & 120,742 & 95,128 \\
\hline $\begin{array}{l}\text { Cost of severe hypoglycaemia } \\
-20 \%\end{array}$ & 35,418 & 0.185 & 239,106 & 191,825 & 28,440 & 0.298 & 120,954 & 95,340 \\
\hline Cost of complications $+20 \%$ & 33,295 & 0.185 & 227,608 & 180,327 & 26,413 & 0.298 & 114,159 & 88,544 \\
\hline Cost of complications $-20 \%$ & 37,502 & 0.185 & 250,395 & 203,114 & 30,404 & 0.298 & 127,538 & 101,923 \\
\hline $\begin{array}{l}\text { UKPDS-OM1 equation for } \\
\text { mortality }\end{array}$ & 36,374 & 0.162 & 291,958 & 224,444 & 30,891 & 0.262 & 149,865 & 117,742 \\
\hline $\begin{array}{l}\text { UKPDS-OM2 equation for } \\
\text { macrovascular }\end{array}$ & 35,711 & 0.181 & 232,210 & 197,193 & 28,553 & 0.289 & 116,358 & 98,716 \\
\hline 20-year time horizon & 38,514 & 0.167 & 283,164 & 230,840 & 31,224 & 0.274 & 141,751 & 113,883 \\
\hline 30-year time horizon & 35,315 & 0.181 & 243,262 & 195,048 & 28,182 & 0.294 & 121,665 & 95,714 \\
\hline $0 \%$ discount rate & 31,758 & 0.277 & 154,258 & 114,723 & 20,223 & 0.424 & 70,964 & 47,661 \\
\hline $5 \%$ discount rate & 35,918 & 0.144 & 302,563 & 249,889 & 31,345 & 0.240 & 157,489 & 130,353 \\
\hline Cost of drugs $+20 \%$ & 46,456 & 0.185 & 298,889 & 251,608 & 37,820 & 0.298 & 152,400 & 126,786 \\
\hline Cost of drugs $-20 \%$ & 24,341 & 0.185 & 179,113 & 131,833 & 18,996 & 0.298 & 89,296 & 63,682 \\
\hline $\begin{array}{l}\text { QoL decrements of complica- } \\
\text { tions }+20 \%\end{array}$ & 35,399 & 0.189 & 234,006 & 187,713 & 28,408 & 0.302 & 119,375 & 94,072 \\
\hline $\begin{array}{l}\text { QoL decrements of complica- } \\
\text { tions }-20 \%\end{array}$ & 35,399 & 0.181 & 244,215 & 195,903 & 28,408 & 0.295 & 122,359 & 96,424 \\
\hline $\begin{array}{l}\text { QoL decrements of complica- } \\
\text { tions in subsequent years set } \\
\text { to } 0\end{array}$ & 35,399 & 0.181 & 243,948 & 195,689 & 28,408 & 0.297 & 121,196 & 95,508 \\
\hline $\begin{array}{l}\text { Assuming QoL decrement } \\
0.00195^{\mathrm{a}} \text { instead of } 0.006 \text { per } \\
\text { unit increase in } \mathrm{BMI}^{\mathrm{a}}\end{array}$ & 35,399 & 0.154 & 286,517 & 229,836 & 28,408 & 0.230 & 156,700 & 123,486 \\
\hline $\begin{array}{l}\text { Assuming no QoL impact of } \\
\text { BMI }\end{array}$ & 35,399 & 0.139 & 316,846 & 254,166 & 28,408 & 0.197 & 182,812 & 144,064 \\
\hline $\begin{array}{l}\text { QALY disutility weights from the } \\
\text { Swedish NDR }\end{array}$ & 35,399 & 0.167 & 264,677 & 212,317 & 28,408 & 0.278 & 129,881 & 102,352 \\
\hline $\begin{array}{l}\text { 3-year fixed treatment duration } \\
\text { for intervention drugs until } \\
\text { initiation of insulin }\end{array}$ & 6133 & 0.039 & 321,445 & 157,119 & -1433 & 0.075 & 158,372 & Dominant \\
\hline Probabilistic sensitivity analysis & 29,073 & 0.184 & 213,502 & 157,776 & 27,294 & 0.286 & 125,214 & 95,519 \\
\hline
\end{tabular}

Costs are reported in Swedish Krona

$B M I$ body mass index, ICER incremental cost-effectiveness ratio, NDR National Diabetes Register, $O M$ outcomes model, $Q A L Y S$ qualityadjusted life years, $Q o L$ quality of life, UKPDS UK Prospective Diabetes Study

${ }^{a}$ From UK National Institute for Health and Care Excellence guidelines

\subsection{Sensitivity Analyses}

Overall, results from the deterministic sensitivity analyses indicate that the base-case findings are robust (Table 2). Cost-effectiveness planes for the PSA results are presented in Fig. 2 (from a societal perspective) and Fig. S2 in Online Resource 1 (from a payer perspective), with each point representing the QALY and cost differences of one of the 1000-cohort replicates. The scatterplots indicate that the PSA produced similar results to the base case.

The probability that oral semaglutide is cost effective versus comparators at different willingness-to-pay (WTP) thresholds is presented in Fig. 2. Compared with empagliflozin and sitagliptin, there is a $100 \%$ likelihood that oral semaglutide is cost effective at a WTP threshold of SEK500,000 per QALY gained. 
Fig. 2 Cost-effectiveness planes from $\mathbf{a}, \mathbf{b}$ probabilistic sensitivity analyses and $\mathbf{c}, \mathbf{d}$ acceptability curves from PIONEER 2 and PIONEER 3 (societal perspective). a, c Oral semaglutide $14 \mathrm{mg}$ vs. empagliflozin $25 \mathrm{mg}$; b, d Oral semaglutide $14 \mathrm{mg}$ vs. sitagliptin $100 \mathrm{mg}$. Mean values in the scatter plots are indicated by the orange points. $Q A L Y S$ quality-adjusted life-years, $S E K$ Swedish Krona

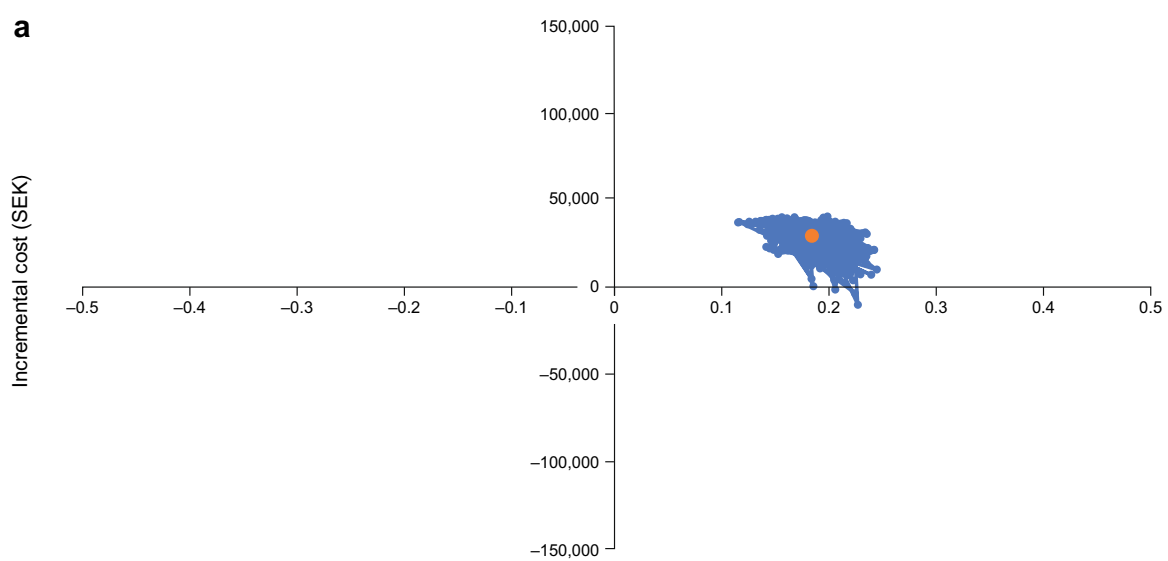

Incremental QALYS
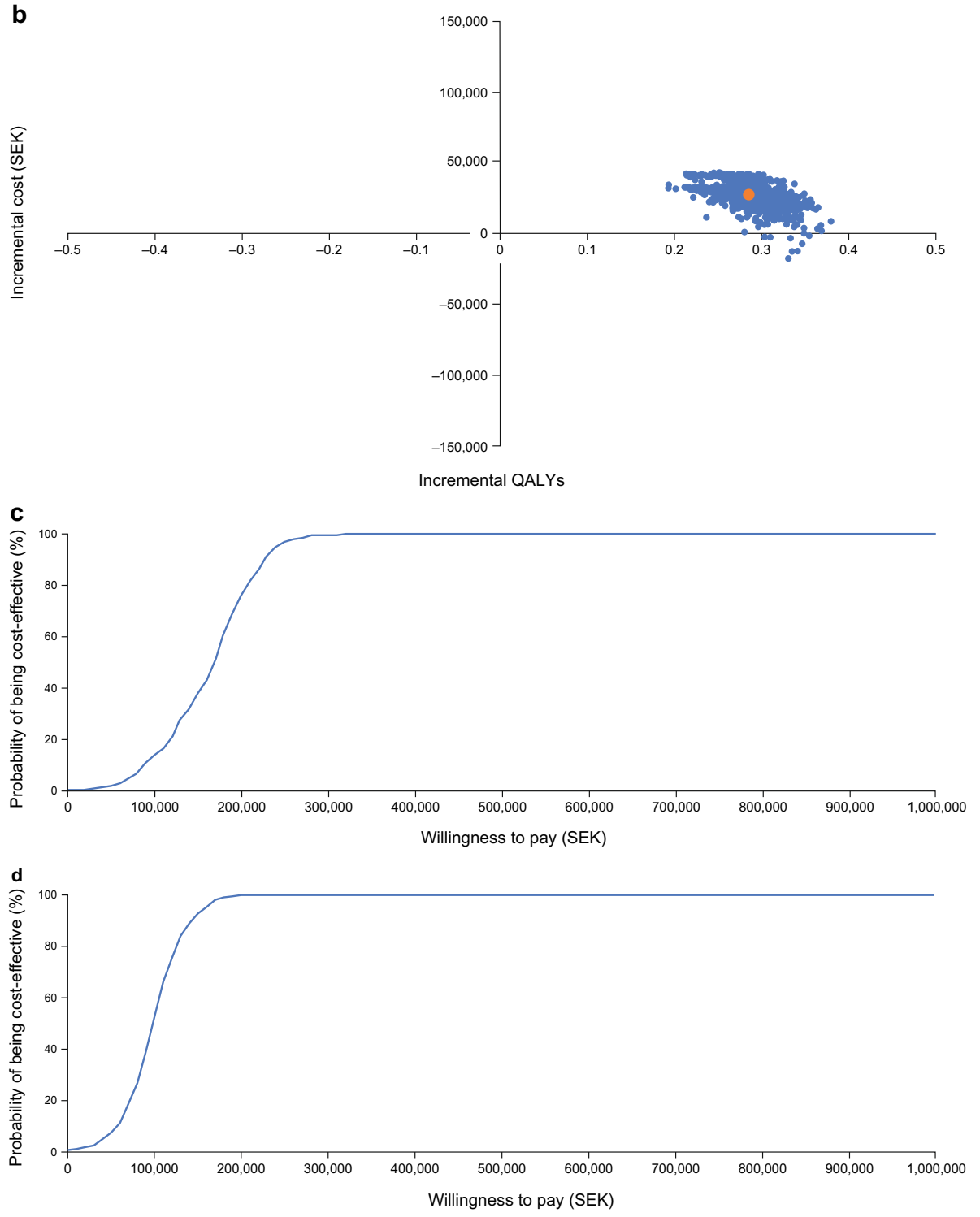


\subsection{Analyses of Additional Cardiovascular Effects}

Applying cardiovascular effects to the proportion of patients in PIONEER 2 and PIONEER 3 who met the PIONEER 6 inclusion criteria (17\% of the total patients in PIONEER 2 and $21 \%$ in PIONEER $3[15,16]$ ) had a moderate impact on cost effectiveness. Using the probabilistic analysis led to slightly different base-case costs than the primary analysis. The ICER improved (reduced) from SEK213,502 per QALY in the base case to SEK173,563 per QALY for oral semaglutide versus empagliflozin (payer perspective) (Table 3). Similarly, the ICER improved from SEK125,214 per QALY to SEK107,014 per QALY for oral semaglutide versus sitagliptin (Table 3). When cardiovascular effects were applied to all patients in PIONEER 2 and PIONEER 3, the ICER improved to SEK101,581 per QALY for oral semaglutide versus empagliflozin and SEK91,707 per QALY for oral semaglutide versus sitagliptin (Table 3). Data for the deterministic sensitivity analyses are shown in Table S9 in Online Resource 1, and scatter plots for all scenarios and analysis methods are shown in Figs. S3 and S4 in Online Resource 1.

\section{Discussion}

The head-to-head PIONEER 2 and PIONEER 3 trials showed that oral semaglutide $14 \mathrm{mg}$ improved glycaemic control over 52 weeks compared with empagliflozin $25 \mathrm{mg}$ and sitagliptin $100 \mathrm{mg}$ in patients with T2D who had inadequate glycaemic control on one or two existing oral glucose-lowering drugs $[15,16]$. The present long-term cost-effectiveness analysis suggests that greater efficacy in terms of improvement in $\mathrm{HbA}_{1 \mathrm{c}}$ results in a reduced cumulative incidence of diabetes-related micro- and macrovascular complications, and increased QALYs. The model also indicates that a delay in the time to initiation of rescue medication with oral semaglutide versus empagliflozin and sitagliptin also reduces the burden of hypoglycaemia, especially if, as modelled here, insulin is used for rescue. Furthermore, the decrease in diabetes-related complications associated with oral semaglutide yields cost savings that partially offset its higher treatment costs versus both empagliflozin and sitagliptin. Oral semaglutide $14 \mathrm{mg}$ was considered to be cost effective based on a WTP threshold of SEK500,000 per QALY gained. In Sweden, there is no fixed limit of how much a QALY might cost for the treatment to be cost effective; however, the National Board of Health and Welfare has presented guidelines stating that costs below SEK500,000/QALY are considered low to medium, whereas costs above that level are considered high [50,51].

Our results, from a Swedish societal perspective, are consistent with long-term cost-effectiveness analyses based on data from the PIONEER programme in the UK setting [52]. When analyses were performed from a healthcare payer perspective using the IQVIA CORE Diabetes Model and projected over a 50-year time horizon, oral semaglutide was associated with improvements in quality-adjusted life expectancy of 0.09 QALYs versus empagliflozin $25 \mathrm{mg}, 0.20$ QALYs versus sitagliptin $100 \mathrm{mg}$ and 0.07 QALYs versus injectable liraglutide $1.8 \mathrm{mg}$. Direct costs over a patient's lifetime were higher with oral semaglutide (pounds sterling [£] +963-971) than with empagliflozin and sitagliptin, but lower than for liraglutide (-£1551). Consistent with the present analysis, oral semaglutide was associated with a reduced incidence of diabetes-related complications versus all three comparators. In the UK setting, oral semaglutide $14 \mathrm{mg}$ was associated with ICERs of $£ 11,006$ and $£ 4930$ per QALY gained versus empagliflozin $25 \mathrm{mg}$ and sitagliptin $100 \mathrm{mg}$, respectively, and was more effective and less costly than liraglutide $1.8 \mathrm{mg}$ [52].

Choosing treatment regimens that are both effective and cost effective is becoming increasingly important as the prevalence of T2D continues to grow. Indeed, achieving improvements in glycaemic control in a cost-effective manner is crucial to the future management of T2D. A recent cost-of-control analysis compared oral semaglutide $14 \mathrm{mg}$ with injectable GLP-1RAs (twice-daily exenatide, once-daily liraglutide, once-daily lixisenatide, once-weekly dulaglutide, once-weekly extended-release exenatide and once-weekly semaglutide) in terms of the cost per patient achieving $\mathrm{HbA}_{1 \mathrm{c}}$ targets from a healthcare payer perspective in the US, based on a published network meta-analysis [53]. For the treatment target of $\mathrm{HbA}_{1 \mathrm{c}}<7.0 \%$, once-weekly semaglutide 1 $\mathrm{mg}$ and once-daily oral semaglutide $14 \mathrm{mg}$ were associated with the lowest costs of control (US\$12,653 and US\$13,587 per patient achieving target, respectively), while twice-daily exenatide $10 \mu \mathrm{g}$ was found to have the highest cost of control (US\$20,695 per patient achieving target) [53].

As with any economic evaluation of long-term chronic diseases, a limitation of this analysis is the use of shortterm clinical data to simulate the course of the disease over a 40-year time horizon. However, in the absence of longterm real-world information, the use of a simulation model based on clinical assumptions and long-term risk equations provides a relevant approach to assess the cost effectiveness of oral semaglutide and inform healthcare decisions. The validated IHE-DCM was used, which has a predictive accuracy in line with other models of T2D [22]. This analysis is applicable to cost-effectiveness analyses of diabetes in Sweden as it is based on the Swedish NDR for risks, healthcare system and costs $[32,54]$. A limitation to the study is the use of mortality risk prediction equations from the UKPDS-OM2. While the UKPDS study is based on a UK cohort enrolled several decades ago, these risk equations are well-established and are commonly used in cost-effectiveness applications in T2D. Of course, in the real world, healthcare budgets and the availability of newer medications also have to be considered. 
Table 3 Cost-effectiveness analyses incorporating cardiovascular effects for patients in PIONEER 2 and PIONEER 3 (probabilistic sensitivity analyses)

\begin{tabular}{|c|c|c|c|c|c|c|c|c|c|}
\hline & \multicolumn{3}{|l|}{ Base case } & \multicolumn{3}{|c|}{$\begin{array}{l}\text { Cardiovascular effects applied to patients } \\
\text { from PIONEER } 2 \text { and } 3 \text { meeting the } \\
\text { PIONEER } 6 \text { inclusion criteria }{ }^{\mathrm{a}}\end{array}$} & \multicolumn{3}{|c|}{$\begin{array}{l}\text { Cardiovascular effects applied to all } \\
\text { patients in PIONEER } 2 \text { and } 3\end{array}$} \\
\hline & $\begin{array}{l}\text { Oral sema- } \\
\text { glutide } \\
14 \mathrm{mg}\end{array}$ & $\begin{array}{l}\text { Empagliflo- } \\
\text { zin } 25 \mathrm{mg}\end{array}$ & Increment & $\begin{array}{l}\text { Oral sema- } \\
\text { glutide } \\
14 \mathrm{mg}\end{array}$ & $\begin{array}{l}\text { Empagliflo- } \\
\text { zin } 25 \mathrm{mg}\end{array}$ & Increment & $\begin{array}{l}\text { Oral sema- } \\
\text { glutide } \\
14 \mathrm{mg}\end{array}$ & $\begin{array}{l}\text { Empagliflo- } \\
\text { zin } 25 \mathrm{mg}\end{array}$ & Increment \\
\hline \multicolumn{10}{|c|}{ a) Empagliflozin $25 \mathrm{mg}$} \\
\hline $\begin{array}{l}\text { Treatment } \\
\text { costs }\end{array}$ & 132,657 & 78,660 & 53,997 & 133,518 & 79,397 & 54,121 & 135,197 & 79,901 & 55,297 \\
\hline $\begin{array}{l}\text { Microvascu- } \\
\text { lar costs }\end{array}$ & 207,989 & 217,810 & -9821 & 210,702 & 220,782 & $-10,080$ & 214,431 & 222,309 & -7878 \\
\hline $\begin{array}{l}\text { Macrovascu- } \\
\text { lar costs }\end{array}$ & 254,429 & 259,263 & -4834 & 255,093 & 262,000 & -6907 & 253,733 & 271,425 & $-17,692$ \\
\hline $\begin{array}{l}\text { Hypoglycae- } \\
\text { mia costs }\end{array}$ & 1033 & 1566 & -533 & 1225 & 1842 & -617 & 1250 & 1856 & -606 \\
\hline Indirect costs & 684,534 & 694,802 & $-10,269$ & 676,508 & 691,926 & $-15,418$ & 635,862 & 671,673 & $-35,811$ \\
\hline Total cost & $1,279,609$ & $1,250,535$ & 29,073 & $1,275,821$ & $1,254,106$ & 21,715 & $1,239,223$ & $1,245,308$ & -6085 \\
\hline QALYs & 8.784 & 8.599 & 0.184 & 8.779 & 8.565 & 0.214 & 8.912 & 8.619 & 0.293 \\
\hline $\begin{array}{l}\text { ICER, payer } \\
\text { perspective }\end{array}$ & - & - & 213,502 & - & - & 173,563 & - & - & 101,581 \\
\hline \multirow{3}{*}{$\begin{array}{l}\text { ICER, } \\
\text { societal } \\
\text { perspective }\end{array}$} & - & - & 157,776 & - & - & 101,499 & - & - & Dominant \\
\hline & \multicolumn{3}{|l|}{ Base case } & \multicolumn{3}{|c|}{$\begin{array}{l}\text { Cardiovascular effects applied to patients } \\
\text { from PIONEER } 2 \text { and } 3 \text { meeting the } \\
\text { PIONEER } 6 \text { inclusion } \text { criteria }^{\mathrm{a}}\end{array}$} & \multicolumn{3}{|c|}{$\begin{array}{l}\text { Cardiovascular effects applied to all } \\
\text { patients in PIONEER } 2 \text { and } 3\end{array}$} \\
\hline & $\begin{array}{l}\text { Oral sema- } \\
\text { glutide } \\
14 \mathrm{mg}\end{array}$ & $\begin{array}{l}\text { Sitagliptin } \\
100 \mathrm{mg}\end{array}$ & Increment & $\begin{array}{l}\text { Oral sema- } \\
\text { glutide } \\
14 \mathrm{mg}\end{array}$ & $\begin{array}{l}\text { Sitagliptin } \\
100 \mathrm{mg}\end{array}$ & Increment & $\begin{array}{l}\text { Oral sema- } \\
\text { glutide } \\
14 \mathrm{mg}\end{array}$ & $\begin{array}{l}\text { Sitagliptin } \\
100 \mathrm{mg}\end{array}$ & Increment \\
\hline \multicolumn{10}{|c|}{ b) Sitagliptin $100 \mathrm{mg}$} \\
\hline $\begin{array}{l}\text { Treatment } \\
\text { costs }\end{array}$ & 121,671 & 72,716 & 48,955 & 122,652 & 73,439 & 49,213 & 123,944 & 73,452 & 50,492 \\
\hline $\begin{array}{l}\text { Microvascu- } \\
\text { lar costs }\end{array}$ & 266,314 & 273,848 & -7534 & 268,741 & 276,546 & -7805 & 272,453 & 276,601 & -4148 \\
\hline $\begin{array}{l}\text { Macrovascu- } \\
\text { lar costs }\end{array}$ & 259,532 & 265,174 & -5641 & 260,182 & 266,078 & -5897 & 258,863 & 265,595 & -6731 \\
\hline $\begin{array}{l}\text { Hypoglycae- } \\
\text { mia costs }\end{array}$ & 1188 & 2053 & -865 & 1420 & 2401 & -981 & 1442 & 2402 & -960 \\
\hline Indirect costs & 801,183 & 809,668 & -8485 & 791,655 & 812,246 & $-20,590$ & 754,285 & 811,469 & $-57,184$ \\
\hline Total cost & $1,448,700$ & $1,421,406$ & 27,294 & $1,443,230$ & $1,428,309$ & 14,921 & $1,409,545$ & $1,427,117$ & $-17,572$ \\
\hline QALYs & 8.192 & 7.906 & 0.286 & 8.183 & 7.851 & 0.332 & 8.285 & 7.853 & 0.432 \\
\hline $\begin{array}{l}\text { ICER, payer } \\
\text { perspective }\end{array}$ & - & - & 125,214 & - & - & 107,014 & - & - & 91,707 \\
\hline $\begin{array}{l}\text { ICER, } \\
\text { societal } \\
\text { perspective }\end{array}$ & - & - & 95,519 & - & - & 44,964 & - & - & Dominant \\
\hline
\end{tabular}

Costs are reported in Swedish Krona

ICER incremental cost-effectiveness ratio, QALYs quality-adjusted life-years

${ }^{\mathrm{a}} 17 \%$ of the total patients in PIONEER 2 and $21 \%$ in PIONEER 3 
Modelling tends to introduce a degree of uncertainty, but our assumptions were conservative and were supported by sensitivity analyses. When the simulations used different risk equations or cost and QoL parameters, the overall conclusion regarding the cost effectiveness of oral semaglutide was unchanged. The use of PIONEER data, rather than observational real-world data, may be considered another limitation of the analysis; however, there is invariably a time lag until real-world evidence becomes available after a medication is approved for clinical use. Given the stringent nature of clinical trials, it can be assumed that the clinical benefits of oral semaglutide (as with all medications) may not fully translate in the real world due to non-adherence to treatment and other factors. Finally, we also acknowledge that although the current model assumes the use of insulin as rescue medication, other glucose-lowering medications were permitted as rescue in PIONEER 2 and 3; however, this assumption was essential to avoid overcomplicating the model.

A strength of the current study is that exploratory scenario analyses were conducted, applying cardiovascular effects. Incorporating these effects, sourced from cardiovascular outcomes trials, provided better health outcomes for all study treatments, and oral semaglutide in particular. Applying cardiovascular benefits to patients matching the inclusion criteria of PIONEER 6 (17\% for PIONEER 2 and 21\% for PIONEER 3) at baseline had a moderate effect on ICERs for oral semaglutide of SEK173,563 and SEK107,014 per QALY gained versus empagliflozin and sitagliptin, respectively. Including additional cardiovascular effects for all patients had a greater impact, with ICERs for oral semaglutide of SEK101,581 and SEK91,707 per QALY gained versus empagliflozin and sitagliptin, respectively. Although the true value of the cardiovascular effects of treatment in these study populations is not known, the scenario analyses conducted suggest that oral semaglutide is associated with additional benefits compared with both empagliflozin and sitagliptin, although the magnitude of this effect is uncertain. It should be noted that results from cardiovascular outcomes trials have not been easily transferred into comparative health economic analyses because of the heterogeneity of trial designs, patient populations and use of background therapy. These results should also be interpreted with caution due to the use of data from non-inferiority trials.

Another strength of the current study is that head-tohead data on treatment effects were used rather than data from indirect analyses. PIONEER 2 and 3 were international studies that included not only Caucasian patients but also participants of other ethnicities who had T2D that was uncontrolled on metformin (with or without sulphonylurea in PIONEER 3) $[15,16]$. Thus, the participants in these trials can be considered representative of patients who were eligible for treatment intensification in Sweden. In addition, the use of 52-week data from the PIONEER trials, matching the annual cycle length of the model, represents a further strength of the analysis. Of note, the trial product estimand was used for these analyses, which assumes that patients remain on treatment and do not require rescue medication. Although the treatment policy estimand (which uses data regardless of treatment discontinuation and rescue medication use) was the primary estimand in PIONEER 2 and PIONEER 3, it was inappropriate to use it for a long-term cost-effectiveness analysis without adjusting for the clinical effects and associated costs of rescue medication used during the study.

\section{Conclusion}

Oral semaglutide $14 \mathrm{mg}$ was projected to be a cost-effective option versus empagliflozin $25 \mathrm{mg}$ and sitagliptin $100 \mathrm{mg}$ for the treatment of T2D in patients inadequately controlled on one or two oral glucose-lowering drugs, and may address current unmet needs for patients, clinicians and payers in Sweden.

Supplementary Information The online version contains supplementary material available at https://doi.org/10.1007/s41669-021-00317-z.

Acknowledgements The authors wish to acknowledge medical writing support provided by Stephen Purver of Axis, a division of Spirit Medical Communications Group Ltd, and Emma Marshman, a contract writer working on behalf of Axis, funded by Novo Nordisk A/S, in accordance with Good Publication Practice 3 (GPP3) guidelines (www. ismpp.org/gpp3). Thanks are also extended to Klaus Kallenbach of Novo Nordisk for reviewing the manuscript.

\section{Declarations}

Funding This study was funded by Novo Nordisk A/S, Denmark.

Conflict of interest Björn Eliasson reports personal fees (expert panels, lectures) from Amgen, AstraZeneca, Boehringer Ingelheim, Eli Lilly, Merck Sharp \& Dohme, Mundipharma, Navamedic, NovoNordisk and RLS Global, and grants and personal fees from Sanofi, all outside the submitted work. Asa Ericsson and Barrie Chubb are employees and shareholders of Novo Nordisk A/S. Adam Fridhammar, Andreas Nilsson and Sofie Persson are employees of the Swedish Institute for Health Economics, which provides consulting services for governmental bodies, academic institutions and commercial life science enterprises (including Novo Nordisk A/S).

Availability of data and material Data will be shared with researchers who submit a research proposal approved by an independent review board. Access request proposals can be found at novonordisktrials.com. Data will be made available after research completion and approval of the product and product use in the EU and the US. Individual participant data will be shared in datasets in a de-identified and anonymised format. There will not be any limitations on how these data can be used. 
Code availability The economic model (IHE-DCM) used in this study is proprietary intellectual property. For access, please contact Sofie Persson at IHE (sofie.persson@ihe.se).

Author contributions All authors contributed to the design of the study. $\mathrm{AF}, \mathrm{AN}$ and SP conducted the analyses. All authors contributed to the interpretation of the results and the creation of this manuscript.

Ethics approval Not applicable.

Consent to participate Not applicable.

Consent for publication Not applicable.

Open Access This article is licensed under a Creative Commons Attribution-NonCommercial 4.0 International License, which permits any non-commercial use, sharing, adaptation, distribution and reproduction in any medium or format, as long as you give appropriate credit to the original author(s) and the source, provide a link to the Creative Commons licence, and indicate if changes were made. The images or other third party material in this article are included in the article's Creative Commons licence, unless indicated otherwise in a credit line to the material. If material is not included in the article's Creative Commons licence and your intended use is not permitted by statutory regulation or exceeds the permitted use, you will need to obtain permission directly from the copyright holder. To view a copy of this licence, visit http://creativecommons.org/licenses/by-nc/4.0/.

\section{References}

1. Andersson E, Persson S, Hallén N, Ericsson Å, Thielke D, Lindgren $\mathrm{P}$, et al. Costs of diabetes complications: hospital-based care and absence from work for 392,200 people with type 2 diabetes and matched control participants in Sweden. Diabetologia. 2020;63(12):2582-94.

2. Bommer C, Sagalova V, Heesemann E, Manne-Goehler J, Atun $\mathrm{R}$, Bärnighausen T, et al. Global economic burden of diabetes in adults: projections from 2015 to 2030. Diabetes Care. 2018;41(5):963-70.

3. Stratton IM, Adler AI, Neil HAW, Matthews DR, Manley SE, Cull CA, et al. Association of glycaemia with macrovascular and microvascular complications of type 2 diabetes (UKPDS 35): prospective observational study. BMJ. 2000;321(7258):405-12.

4. Rawshani A, Rawshani A, Franzén S, Eliasson B, Svensson AM, Miftaraj M, et al. Mortality and cardiovascular disease in type 1 and type 2 diabetes. N Engl J Med. 2017;376(15):1407-18.

5. Rawshani A, Rawshani A, Franzén S, Sattar N, Eliasson B, Svensson AM, et al. Risk factors, mortality, and cardiovascular outcomes in patients with type 2 diabetes. N Engl J Med. 2018;379(7):633-44.

6. Tancredi M, Rosengren A, Svensson AM, Pivodic A, Gudbjörnsdottir S, Wedel $\mathrm{H}$, et al. Glycaemic control and excess risk of major coronary events in patients with type 2 diabetes: a population-based study. Open Heart. 2019;6(2):e000967.

7. Baxter M, Hudson R, Mahon J, Bartlett C, Samyshkin Y, Alexiou $\mathrm{D}$, et al. Estimating the impact of better management of glycaemic control in adults with type 1 and type 2 diabetes on the number of clinical complications and the associated financial benefit. Diabet Med. 2016;33(11):1575-81.

8. Ekström N, Miftaraj M, Svensson AM, Andersson Sundell K, Cederholm J, Zethelius B, et al. Glucose-lowering treatment and clinical results in 163121 patients with type 2 diabetes: an observational study from the Swedish national diabetes register. Diabetes Obes Metab. 2012;14(8):717-26.

9. Eliasson B, Ekelund J, Amberntsson R, Miftaraj M, Svensson AM. Cardiovascular disease in patients with type 2 diabetes and in patients starting empagliflozin treatment: nationwide survey. Diabetes Ther. 2019;10(4):1523-30.

10. Davies MJ, D'Alessio DA, Fradkin J, Kernan WN, Mathieu C, Mingrone G, et al. Management of hyperglycemia in type 2 diabetes, 2018. A consensus report by the American Diabetes Association (ADA) and the European Association for the Study of Diabetes (EASD). Diabetes Care. 2018;41(12):2669-701.

11. Buse JB, Wexler DJ, Tsapas A, Rossing P, Mingrone G, Mathieu C, et al. 2019 update to: Management of hyperglycemia in type 2 diabetes, 2018. A consensus report by the American Diabetes Association (ADA) and the European Association for the Study of Diabetes (EASD). Diabetes Care. 2020;43:487-93.

12. Buckley ST, Bækdal TA, Vegge A, Maarbjerg SJ, Pyke C, Ahnfelt-Rønne J, et al. Transcellular stomach absorption of a derivatized glucagon-like peptide-1 receptor agonist. Sci Transl Med. 2018;10(467):eaar7047.

13. European Medicines Agency. Rybelsus Summary of Product Characteristics. https://www.ema.europa.eu/en/documents/ product-information/rybelsus-epar-product-information_en.pdf. Accessed 1 Jul 2021.

14. Aroda VR, Rosenstock J, Terauchi Y, Altuntas Y, Lalic NM, Morales Villegas EC, et al. PIONEER 1: randomized clinical trial comparing the efficacy and safety of oral semaglutide monotherapy with placebo in patients with type 2 diabetes. Diabetes Care. 2019;42:1724-32.

15. Rodbard HW, Rosenstock J, Canani LH, Deerochanawong C, Gumprecht J, Lindberg S $\varnothing$, et al. Oral semaglutide versus empagliflozin in patients with type 2 diabetes uncontrolled on metformin: the PIONEER 2 trial. Diabetes Care. 2019;42(12):2272-81.

16. Rosenstock J, Allison D, Birkenfeld AL, Blicher TM, Deenadayalan S, Jacobsen JB, et al. Effect of additional oral semaglutide vs sitagliptin on glycated hemoglobin in adults with type 2 diabetes uncontrolled with metformin alone or with sulfonylurea: the PIONEER 3 randomized clinical trial. JAMA. 2019;321(15):1466-80.

17. Pratley R, Amod A, Hoff ST, Kadowaki T, Lingvay I, Nauck M, et al. Oral semaglutide versus subcutaneous liraglutide and placebo in type 2 diabetes (PIONEER 4): a randomised, doubleblind, phase 3a trial. Lancet. 2019;394(10192):39-50.

18. Mosenzon O, Blicher TM, Rosenlund S, Eriksson JW, Heller S, $\mathrm{Hels} \mathrm{OH}$, et al. Efficacy and safety of oral semaglutide in patients with type 2 diabetes and moderate renal impairment (PIONEER 5): a placebo-controlled, randomised, phase 3 a trial. Lancet Diabetes Endocrinol. 2019;7(7):515-27.

19. Husain M, Birkenfeld AL, Donsmark M, Dungan K, Eliaschewitz FG, Franco DR, et al. Oral semaglutide and cardiovascular outcomes in patients with type 2 diabetes. N Engl J Med. 2019;381(9):841-51.

20. Pieber TR, Bode B, Mertens A, Cho YM, Christiansen E, Hertz $\mathrm{CL}$, et al. Efficacy and safety of oral semaglutide with flexible dose adjustment versus sitagliptin in type 2 diabetes (PIONEER 7): a multicentre, open-label, randomised, phase 3 a trial. Lancet Diabetes Endocrinol. 2019;7:528-39.

21. Zinman B, Aroda VR, Buse JB, et al. Efficacy, safety, and tolerability of oral semaglutide versus placebo added to insulin with or without metformin in patients with type 2 diabetes: the PIONEER 8 trial. Diabetes Care. 2019;42(12):2262-71.

22. Lundqvist A, Steen Carlsson K, Johansen P, Andersson E, Willis M. Validation of the IHE Cohort Model of type 2 diabetes and the impact of choice of macrovascular risk equations. PLoS ONE. 2014;9(10):e110235. 
23. Willis M, Fridhammar A, Gundgaard J, Nilsson A, Johansen P. Comparing the cohort and micro-simulation modeling approaches in cost-effectiveness modeling of type 2 diabetes mellitus: a case study of the IHE Diabetes Cohort Model and the Economics and Health Outcomes Model of T2DM. Pharmacoeconomics. 2020;38(9):953-69.

24. The Dental and Pharmaceutical Benefits Agency (TLV). Lyxumia is included in the reimbursement system with limitation (Lyxumia ingår i högkostnadsskyddet med begränsning) [in Swedish]. 2015. https://www.tlv.se/beslut/beslut-lakemedel/begransad-subvention/ arkiv/2015-02-26-lyxumia-ingar-i-hogkostnadsskyddet-medbegransning.html. Accessed 1 Jul 2021.

25. The Dental and Pharmaceutical Benefits Agency (TLV). Xultophy is included in the reimbursement system with limitation (Xultophy ingår i högkostnadsskyddet medbegränsning) [in Swedish]. 2015. https://www.tlv.se/beslut/beslut-lakemedel/begransad-subvention/ arkiv/2015-06-15-xultophy-ingar-i-hogkostnadsskyddet-medbegransning.html. Accessed 1 Jul 2021.

26. Kiadaliri AA, Gerdtham UG, Eliaason B, Steen CK. Cost-utility analysis of glucagon-like peptide-1 agonists compared with dipeptidyl peptidase- 4 inhibitors or neutral protamine hagedorn basal insulin as add-on to metformin in type 2 diabetes in Sweden. Diabetes Ther. 2014;5(2):591-607.

27. Steen Carlsson K, Persson U. Cost-effectiveness of add-on treatments to metformin in a Swedish setting: liraglutide vs sulphonylurea or sitagliptin. J Med Econ. 2014;17(9):658-69.

28. Ericsson $\AA$, Fridhammar A. Cost-effectiveness of once-weekly semaglutide versus dulaglutide and lixisenatide in patients with type 2 diabetes with inadequate glycemic control in Sweden. J Med Econ. 2019;22(10):997-1005.

29. Johansen P, Håkan-Bloch J, Liu AR, Bech PG, Persson S, Leiter LA. Cost effectiveness of once-weekly semaglutide versus onceweekly dulaglutide in the treatment of type 2 diabetes in Canada. Pharmacoecon Open. 2019;3(4):537-50.

30. Clarke PM, Gray AM, Briggs A, Farmer AJ, Fenn P, Stevens RJ, et al. A model to estimate the lifetime health outcomes of patients with type 2 diabetes: the United Kingdom Prospective Diabetes Study (UKPDS) Outcomes Model (UKPDS no. 68). Diabetologia. 2004;47(10):1747-59.

31. Hayes AJ, Leal J, Gray AM, Holman RR, Clarke PM. UKPDS outcomes model 2: a new version of a model to simulate lifetime health outcomes of patients with type 2 diabetes mellitus using data from the 30 year United Kingdom Prospective Diabetes Study: UKPDS 82. Diabetologia. 2013;56(9):1925-33.

32. Kiadaliri AA, Gerdtham UG, Nilsson P, Eliasson B, Gudbjörnsdottir S, Carlsson KS. Towards renewed health economic simulation of type 2 diabetes: risk equations for first and second cardiovascular events from Swedish register data. PLoS ONE. 2013;8(5):e62650.

33. Davis WA, Knuiman MW, Davis TME. An Australian cardiovascular risk equation for type 2 diabetes: the Fremantle Diabetes Study. Intern Med J. 2010;40(4):286-92.

34. Eastman RC, Javitt JC, Herman WH, Dasbach EJ, Zbrozek AS, Dong F, et al. Model of complications of NIDDM. I. Model construction and assumptions. Diabetes Care. 1997;20(5):725-34.

35. Bagust A, Hopkinson PK, Maier W, Currie CJ. An economic model of the long-term health care burden of type II diabetes. Diabetologia. 2001;44(12):2140-55.

36. Tandvårds- och läkemedelsförmånsverkets allmänna råd. Ändring i Tandvårds- och läkemedelsförmånsverkets allmänna råd (TLVAR 2003:2) om ekonomiska utvärderingar [in Swedish]. https://www.tlv.se/download/18.467926b615d084471ac3230c/ 1510316374332/TLVAR_2017_1.pdf. Accessed 1 Jul 2021.

37. Kahn SE, Haffner SM, Heise MA, Herman WH, Holman RR, Jones NP, et al. Glycemic durability of rosiglitazone, metformin, or glyburide monotherapy. N Engl J Med. 2006;355(23):2427-43.
38. Willis M, Asseburg C, Nilsson A, Johnsson K, Kartman B. Multivariate prediction equations for $\mathrm{HbA}_{1 \mathrm{c}}$ lowering, weight change, and hypoglycemic events associated with insulin rescue medication in type 2 diabetes mellitus: informing economic modeling. Value Health. 2017;20:357-71.

39. Aroda VR, Saugstrup T, Buse JB, Donsmark M, Zacho J, Davies MJ. Incorporating and interpreting regulatory guidance on estimands in diabetes clinical trials: the PIONEER 1 randomized clinical trial as an example. Diabetes Obes Metab. 2019;21(10):2203-10.

40. Steen Carlsson K, Andersson E, Lundqvist A, Willis M. Påverkbara kostnader för typ 2-diabetes år 2020 och år 2030 i Sverige - prognoser med IHE Cohort Model of type 2 diabetes. IHE Rapport 2015 [in Swedish]. https://ihe.se/wp-content/uploads/2017/ 10/IHE-Rapport_2015_1.pdf. Accessed 1 Jul 2021.

41. Statistics Sweden. Average monthly salary by sex and age [in Swedish]. www.scb.se. Accessed 1 Feb 2021.

42. Ekonomifakta. Social fees [in Swedish]. www.ekonomifakta.se. Accessed 1 Feb 2021.

43. Persson S, Johansen P, Andersson E, Lindgren P, Thielke D, Thorsted BL, et al. Days absent from work as a result of complications associated with type 2 diabetes: evidence from 20 years of linked national registry data in Sweden. Diabetes Obes Metab. 2020;22(9):1586-97.

44. Geelhoed-Duijvestijn PH, Pedersen-Bjergaard U, Weitgasser R, Lahtela J, Jensen MM, Östenson CG. Effects of patient-reported non-severe hypoglycemia on healthcare resource use, work-time loss, and wellbeing in insulin-treated patients with diabetes in seven European countries. J Med Econ. 2013;16(12):1453-61.

45. Jönsson B; CODE-2 Advisory Board. Revealing the cost of type II diabetes in Europe. Diabetologia. 2002;45(7):S5-12.

46. Beaudet A, Clegg J, Thuresson PO, Lloyd A, McEwan P. Review of utility values for economic modeling in type 2 diabetes. Value Health. 2014;17(4):462-70.

47. Evans M, Khunti K, Mamdani M, Galbo-Jørgensen CB, Gundgaard J, Bøgelund M, et al. Health-related quality of life associated with daytime and nocturnal hypoglycaemic events: a time trade-off survey in five countries. Health Qual Life Outcomes. 2013;11:90.

48. Zinman B, Wanner C, Lachin JM, Fitchett D, Bluhmki E, Hantel $\mathrm{S}$, et al. Empagliflozin, cardiovascular outcomes, and mortality in type 2 diabetes. N Engl J Med. 2015;373(22):2117-28.

49. Green JB, Bethel MA, Armstrong PW, Buse JB, Engel SS, Garg $\mathrm{J}$, et al. Effect of sitagliptin on cardiovascular outcomes in type 2 diabetes. N Engl J Med. 2015;373(3):232-42.

50. Carlsson P, Anell A, Eliasson M. Hälsoekonomi får allt större roll för sjukvårdens prioriteringar [in Swedish]. Lakartidningen. 2006; 103:3617-23.

51. National Board of Health and Welfare (Socialstyrelsen). Bilaga 4, Metod, Nationella riktlinjer för diabetesvården 2010 — Stöd för styrning och ledning [in Swedish]. Stockholm: Socialstyrelsen; 2010.

52. Bain SC, Hansen BB, Malkin SJP, Nuhoho S, Valentine WJ, Chubb B, et al. Oral semaglutide versus empagliflozin, sitagliptin and liraglutide in the UK: long-term cost-effectiveness analyses based on the PIONEER clinical trial programme. Diabetes Ther. 2020;11(1):259-77.

53. Hansen BB, Nuhoho S, Ali SN, Dang-Tan T, Valentine WJ, Malkin SJP, et al. Oral semaglutide versus injectable glucagon-like peptide-1 receptor agonists: a cost of control analysis. J Med Econ. 2020;23(6):650-8.

54. Ericsson A, Lundqvist A. Cost effectiveness of insulin degludec plus liraglutide (IDegLira) in a fixed combination for uncontrolled type 2 diabetes mellitus in Sweden. Appl Health Econ Health Policy. 2017;15:237-48. 